\title{
Strategic Business Planning in Key to Effective Diagnosis and Management of Blood Disorders in Developing Countries
}

\author{
Erhabor $\mathrm{O}^{1^{*}}$, Abdulrahaman $\mathrm{Y}^{1}$, Egenti BN ${ }^{2}$, Buhari $\mathrm{H}^{1}$, Fredricks $\mathrm{C}^{3}$, Adias $\mathrm{TC}^{4}$, Echonwere $\mathrm{B}^{4}$ and Okara $\mathrm{GC}^{5}$ \\ ${ }^{1}$ Department of Haematology \& Blood Transfusion Science, Faculty of Medical Laboratory Science, Usmanu Danfodiyo University, Sokoto, Nigeria \\ ${ }^{2}$ Department of Community Health, University of Abuja, Airport Road, Nigeria \\ ${ }^{3}$ College of Health Sciences, University of Abuja, Airport Road, Nigeria \\ ${ }^{4}$ Department of Medical Laboratory Science, Rivers State University of Science and Technology, Port-Harcourt, Rivers State, Nigeria \\ ${ }^{5}$ Dr Hassan's Hospital and Diagnostic Centre, Maitama, Abuja, Nigeria
}

*Corresponding author: Osaro Erhabor, Department of Haematology \& Blood Transfusion Science, Faculty of Medical Laboratory Science, Usmanu Danfodiyo University, Sokoto, Nigeria, Tel: +447932363217; E-mail: n_osaro@yahoo.com

Received date: May 06, 2016, Accepted date: May 09, 2016, Publication date: May 11, 2016

Copyright: (c) 2016 Erhabor O, et al. This is an open-access article distributed under the terms of the Creative Commons Attribution License, which permits unrestricted use, distribution, and reproduction in any medium, provided the original author and source are credited.

Citation: Erhabor O, Abdulrahaman Y, Egenti BN, Buhari H, Fredricks C, et al. (2016) Strategic Business Planning in Key to Effective Diagnosis and Management of Blood Disorders in Developing Countries. J Blood Disord Transfus 7: 350. doi:10.4172/2155-9864.1000350

A strategy is a high level plan of action designed to achieve a longterm overall aim. It is aimed at achieving one or more goals under conditions of uncertainty. Strategy is important because the resources available to achieve these goals are usually limited. Strategy generally involves setting goals, determining actions to achieve the goals, and mobilizing resources to execute the actions. Strategy is about shaping the future (getting to a desirable ends with available means). It is the finding, formulating and developing of a doctrine that ensure longterm success if followed faithfully and objectively. Strategic planning allows us to prioritize, focus energy and resources, identify and remove waste and strengthen operations, towards achieving organizational goals. Regulatory requirement and changing customer requirements may affect the way blood disorders are diagnosed and managed in developing countries in future, funds available for diagnosis and management of blood disorders is on the decline, population in most developing countries is gradually aging due to advances in technology and medical care, there is an increasing high incidence of blood disorders and there is a growing shift from treating diseases to treating predisposition. Health professionals responsible for the diagnosis and management of blood disorders in developing countries may need to work smartly and collaboratively to ensure cost effectiveness (value for money) without compromising on quality of service delivered. Future implementable strategic business plans in developing countries to ensure a continually improving diagnostic service and evidence-based best practices in the management of blood disorders include; equipment leasing rather that outright purchase, bulk buying of reagents and consumables (through a $3^{\text {rd }}$ party agent), public private partnership in the ownership and management of fit for purpose diagnostic laboratories, cross-disciplinary working, use of high throughput analyzers, remote access to analyzers and validation of results and outsourcing of low volume expensive diagnostic test associated with low stability and expensive reagents and equipment. The only way the diagnostic laboratories in developing countries particularly those in sub Saharan Africa can achieve her objective of meeting the changing requirements of customers with blood disorders and make profit is to implement the principles of long-term strategic business planning. 